\title{
A Rare Case of Umbilical Epidermoid Cyst
}

\section{Praveen Shankar Padasali*, Gudekote Ravikumara, Sundeep VK and Shankaregowda VS}

Sapthagiri Institute of Medical Sciences, Bangalore, India

\begin{abstract}
Epidermoid cysts are one of the most common benign skin tumors, although they are rarely found in the umbilicus of adult. The vast majority of epidermoid cysts are of not great consequences, but some in certain places are cause for concern and leads to misdiagnosis and inappropriate treatment. Herein we reported the case of umbilical epidermal cyst in a 40 year adult which was present since 15 years. This mass has been misdiagnosed as lipoma, irreducible umbilical hernia and umbilical dermoid.
\end{abstract}

Keywords: Umbilical; Epidermoid cyst; Umbilical dermoid; Irreducible umbilical hernia

\section{Case History}

A 40 year old man presented with a swelling in the umbilical region for past 15 years (Figure 1). The swelling in the umbilicus was diagnosed as irreducible umbilical hernia by referred physician. $\mathrm{He}$ was asymptomatic except for slight pain at the lesion. There was no history of pain abdomen, vomiting, discharge from umbilicus, decrease in size of swelling and previous surgeries . On examination there was no tenderness, soft in consistency skin not pinch able, mobile in all directions. Ultrasound of abdomen revealed the subcutaneous mass, which did not penetrate into abdominal cavity or connection to internal organs. Total excision was performed under local anaesthesia (Figure 2). Exploration during operation showed the mass did not have duct or tract connecting it to the abdominal cavity. The patient's postoperative course was uneventful .The sutures were removed after 10 days had a good cosmetic result. Histological assessment revealed an epidermal cyst; there was no malignancy $[1,2]$.

\section{Discussion}

An epidermoid cyst is a benign cyst usually found on the skin. The cyst develops out of ectodermal tissue. Histologically, it is made of a thin layer of squamous epithelium [3]. Epidermoid cysts can appear anywhere on the skin, but are most common on the scalp, ears, back,

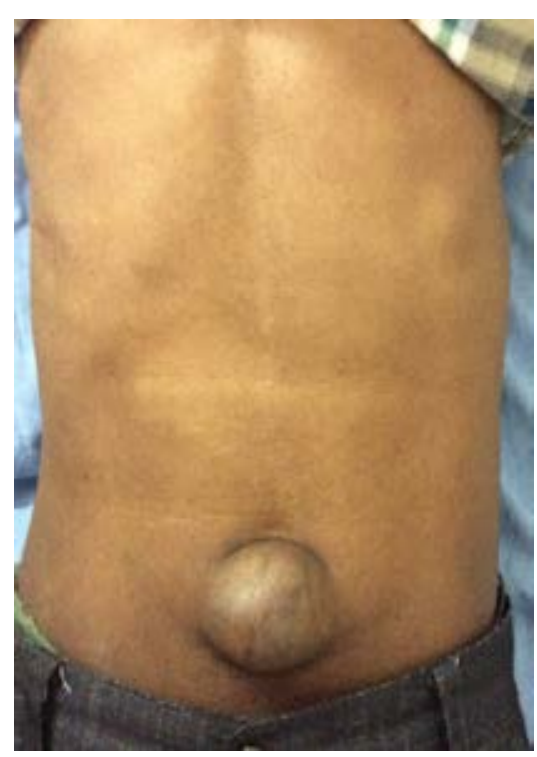

Figure 1: Umbilical Epidermoid Cyst in a 40 Year Old adult.

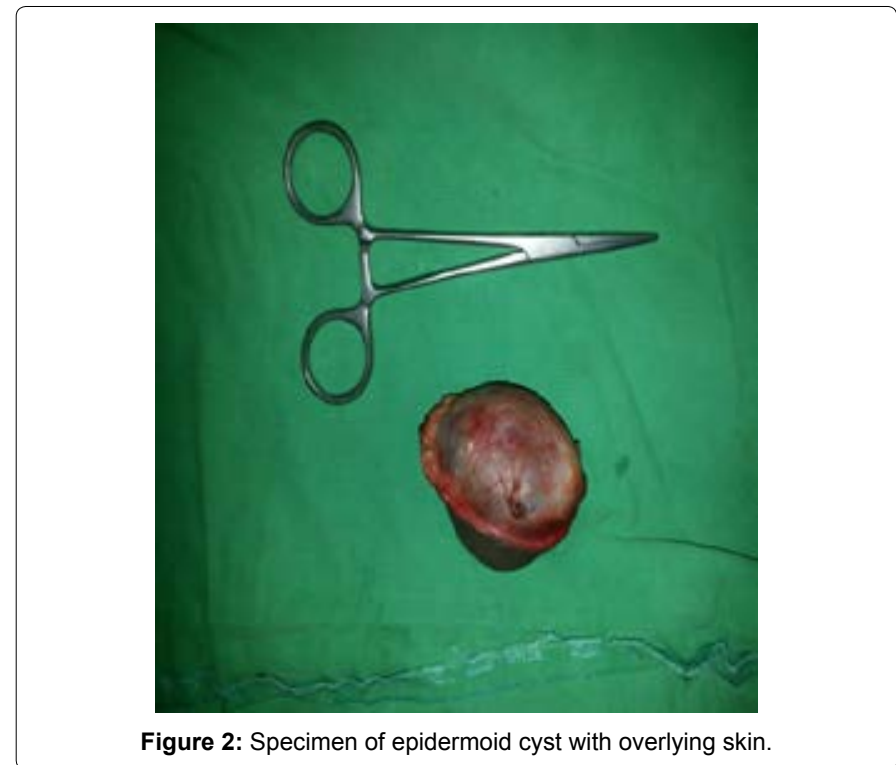

face, trunk and upper arm, are common sites for epidermoid cysts, though they may occur anywhere on the body except the palms of the hands and soles of the feet $[4,5]$.

In males a common place for them to develop is the scrotum and chest. They are more common in hairier areas, where in cases of long duration they could result in hair loss on the skin surface immediately above the cyst. They are smooth to the touch, vary in size, soft in consistency and are generally round in shape. Hereditary causes of sebaceous cysts include Gardner's syndrome and basal cell nevus syndrome. This mass has been misdiagnosed as lipoma, neurofibroma, schwannoma, umbilical adenoma, Sister Mary joseph nodule, caput medusa, haemangioma, irreducible umbilical hernia and umbilical

*Corresponding author: Pandasali PS, MBBS, MS, Assistant professor, General surgery, Sapthagiri Institute of Medical Sciences, Bangalore, India-560090, Tel: +919880981480; E-mail: pravsp12@gmail.com

Received October 21, 2014; Accepted January 23, 2014; Published February 01,2015

Citation: Padasali PS, Ravikumara G, Sundeep VK, Shankaregowda VS (2015) A Rare Case of Umbilical Epidermoid Cyst. Surgery Curr Res 5: 215 doi:10.4172/2161-1076.1000215

Copyright: @ 2015 Padasali PS, et al. This is an open-access article distributed under the terms of the Creative Commons Attribution License, which permits unrestricted use, distribution, and reproduction in any medium, provided the original author and source are credited. 
desmoid.

Slow growing and often painless, epidermoid cysts rarely cause problems or need treatment. If it's painful, ruptured or infected then excision is the treatment. Surgical excision of a epidermoid cyst is a simple procedure to completely remove the sac and its contents [4]. An infected cyst may require oral antibiotics or other treatment before or after excision.

\section{Conclusion}

Thus we report the case of epidermal cyst on the umbilicus, which is one of the rare sites of presentation. The majority of epidermoid cysts are of no great consequences, but presentation in certain places is cause for concern and leads to diagnostic dilemma and inappropriate treatment.
Herein we report the case of epidermoid cyst on the umbilicus, which is one of the rare sites of presentation and was never reported.

\section{References}

1. Goldberg R, Prichard B, Gelbard M (1992) Umbilical inflammatory conditions; case report and differential diagnosis. J Emerg Med 10: 151-156.

2. Delacretaz J (1977) Keratotic basal-cell carcinoma arising from an epidermoid cyst. J Dermatol Surg Oncol 3: 310-311.

3. Handa U, Kumar S, Mohan H (2002) Aspiration cytology of epidermoid cyst of terminal phalanx. Diagn Cytopathol 26: 266-267.

4. Klin B, Ashkenazi $H$ (1990) sebaceous cyst excision with minimal surgery American Family Physician 41: 1746-1748.

5. Barnes $L$ (2008) surgical pathology of the head and neck. (3rd edn) New York: Informa Healthcare, USA. 